\title{
Clinical utility of blood neutrophil- lymphocyte ratio in Japanese COPD patients
}

\author{
Kaori Sakurai', Shotaro Chubachi ${ }^{1 *}$ (D), Hidehiro Irie ${ }^{1}$, Akihiro Tsutsumi ${ }^{1}$, Naofumi Kameyama', Takashi Kamatani', \\ Hidefumi Koh², Takeshi Terashima ${ }^{3}$, Hidetoshi Nakamura ${ }^{4}$, Koichiro Asano ${ }^{5}$ and Tomoko Betsuyaku ${ }^{1}$
}

\begin{abstract}
Background: Neutrophil-to-lymphocyte ratio (NLR) is a biomarker of inflammation in chronic obstructive pulmonary disease (COPD) patients. But, a meaningful threshold and the longitudinal changes are unknown. We aimed to investigate the association between NLR and the clinical characteristics of COPD patients and to determine a meaningful threshold and the longitudinal changes for NLR.

Methods: Keio University and its affiliate hospitals conducted an observational COPD cohort study over 3 years. We performed a blood examination and a pulmonary function test. Blood examination was completed at baseline and annually thereafter, at a time when the disease was stable. Two hundred seventy-four patients who had at least 3 blood examinations over 3 years were included.

Results: Baseline NLR was correlated with baseline C-reactive protein (CRP) $(r=0.18, p=0.003)$ and SAA ( $r=0.34$, $p<0.001$ ). We defined an NLR score of 2.7 as the arbitrary cut-off value based on upper quartile points. COPD patients with NLR $\geq 2.7$ were older $(p=0.037)$, had a lower BMI $(p=0.005)$ and a lower \%FEV1 ( $p=0.0003)$ compared to patients with NLR $<2.7$. Receiver-operating-characteristic $(R O C)$ curves showed the optimal cutoff for the baseline NLR in the predicting moderate/severe exacerbation to be 2.7 , which was same as the upper quartile points. Follow-up analysis over 3 years revealed that the differences in the trends of NLR among the three groups based on the categories of exacerbations (moderate or severe, mild, no exacerbation) were significant $(p=0.006)$.
\end{abstract}

Conclusions: NLR is associated with COPD severity and exacerbations. For predicting exacerbations, we estimated the threshold of NLR to be 2.7 at baseline.

Trial registration: Clinical trial registered with the University Hospital Medication Information Network (UMIN000003470, April 10, 2010).

Keywords: COPD, NLR, Acute exacerbation, Comorbidity

\section{Background}

Chronic obstructive pulmonary disease (COPD) is common worldwide and is a major health-care concern [1]. COPD is characterized by low-grade chronic systemic inflammation [2], and several biomarkers such as Creactive protein (CRP) $[3,4]$, IL-6 $[4,5]$ and surfactant protein D (SPD) [6] have been reported to be associated with increased risk of death in COPD patients. Although

\footnotetext{
* Correspondence: bachibachi472000@live.jp

'Division of Pulmonary Medicine, Department of Medicine, Keio University School of Medicine, 35 Shinanomachi, Shinjuku-ku, Tokyo 160-8582, Japan Full list of author information is available at the end of the article
}

many biomarkers of systemic inflammation have recently been evaluated to identify some features of COPD $[7,8]$, excessive costs and technical factors prevent their clinical use.

Recently, blood neutrophil-to-lymphocyte ratio (NLR) has been shown to be a valuable predictor of inflammatory conditions and is used for risk stratification of different diseases such as acute coronary syndrome [9], pancreatitis [10], sepsis and infectious conditions [11]. This index is a rapid, easy and cost-effective method which is a calculated index derived from a routine complete blood count test in clinical practice [12]. NLR

(c) The Author(s). 2018 Open Access This article is distributed under the terms of the Creative Commons Attribution 4.0 International License (http://creativecommons.org/licenses/by/4.0/), which permits unrestricted use, distribution, and reproduction in any medium, provided you give appropriate credit to the original author(s) and the source, provide a link to the Creative Commons license, and indicate if changes were made. The Creative Commons Public Domain Dedication waiver (http://creativecommons.org/publicdomain/zero/1.0/) applies to the data made available in this article, unless otherwise stated. 
has been reported to be higher in exacerbated COPD patients than in stable patients [13] and is associated with severity of COPD $[14,15]$. As with other inflammatory markers, NLR has been reported to vary with time [16, 17]. However, annual time-series data of individual NLR, its distribution and a meaningful threshold in COPD remain to be investigated.

Comorbidities and extrapulmonary manifestations have important contributions to disease expression, disease burden, and survival in COPD patients [18]. Several comorbidities such as heart disease, hypertension, and diabetes [19] are also associated with systemic inflammation. However, the association between these comorbidities and NLR in COPD patients has not been elucidated.

We have been conducting a multicenter, observational cohort study, called the Keio COPD Comorbidity Research (K-CCR), to comprehensively examine the comorbidities of COPD in Japan [20-22].

The specific aims of this study are to determine (a) whether NLR is a biomarker that can reflect the severity of airflow limitation and certain other characteristics of COPD patients, (b) if it can predict future exacerbations and (c) if it is associated with any comorbidities. We thus monitored NLR and other known blood biomarkers in Japanese COPD patients over 3 years to evaluate its stability as a biomarker in patients at steady state and investigated its association with a variety of clinical aspects of COPD.

\section{Methods}

\section{Study population}

The overall design of the K-CCR has been previously published [20, 22, 23]. In brief, this study was a 3 -year, prospective observational study that enrolled 572 men and women aged 40-91 years who had been diagnosed with COPD $(n=440)$ or as being at risk for COPD $(n=132)$ by pulmonary physicians from April 2010 to December 2012 $[20,22,23]$. For the purpose of this study, only data from the patients with spirometrically confirmed COPD (FEV1/ forced vital capacity $(\mathrm{FVC})<0.7)$ who had undergone at least 3 blood examinations over 3 years and were not receiving any oral steroid treatments $(n=274)$ were selected and analyzed (Fig. 1). All patients were clinically stable and had no exacerbations and no acute infections for at least 1 month prior to recruitment [20,22, 23]. The ethics committees of the Keio University and its affiliated hospitals approved the study protocol. Each patient provided written, informed consent to analyze and present their data. All aspects of the study conformed to the principles of the Declaration of Helsinki adopted by the 59th WMA General Assembly, Seoul, Republic of Korea, October 2008.

\section{Assessment of clinical parameters}

Complete medical and smoking histories, as well as information regarding the current pharmacologic treatments, were obtained on enrolment and annually thereafter [20, 22]. All patients were assessed by spirometry and chest computed tomography (CT) imaging. On the CT images, the extent of emphysema was quantified as the ratio of low attenuation area (LAA \%) and the percentage of airway wall area (WA \%) using a custommade software (AZE Ltd., Tokyo, Japan) [22, 23]. Independent investigators judged the number and severity of exacerbations based on the reviews of physicians' medical records, as previously reported [22, 24]. Mild COPD exacerbation was defined as worsening of symptoms that were self-managed (by measures such as an increase in salbutamol use) and resolved without systemic corticosteroids or antibiotics [24]. Moderate COPD exacerbation was defined by the requirement for treatment with systemic corticosteroids and/or antibiotics [24]. Severe COPD exacerbation was defined as one that required hospitalization, including an emergency admission for 24 h [24]. Comorbid diagnoses were established by clinical history and examination findings based on a review of available medical records [20, 21, 23, 24].

\section{Evaluation of neutrophil-to-lymphocyte ratio (NLR) and other inflammatory markers}

Blood samples were collected at baseline and annually thereafter, at a time when the disease was stable. The total numbers of white blood cells (WBCs), neutrophils, and lymphocytes were measured at each participating center. NLR was defined as the absolute neutrophil count divided by the absolute lymphocyte count [9]. Serum C-reactive protein (CRP) levels were measured using a Hitachi Ltd. LABOSPECT 008 devise. Serum amyloid A (SAA) is an acute-phase protein similar to CRP, and its levels were evaluated by latex agglutination immunoassay. The annual rates of change in NLR were measured over 3 years. Excel (Microsoft Inc., Redmond, WA, USA) was used to calculate the derived slope between each of the above measures and the date of data collection [22, 25].

\section{Questionnaires on health-related quality of life}

All patients were clinically stable and had no exacerbations for at least 1 month before study enrollment and on the day of the annual examination [22]. The Japanese version of COPD assessment test (CAT) $[26,27]$ and the St. George's Respiratory Questionnaire (SGRQ) in Japanese were used for the assessment of COPD-specific health status [28-30]. All of the questionnaires were completed by the patients themselves at home [20]. 


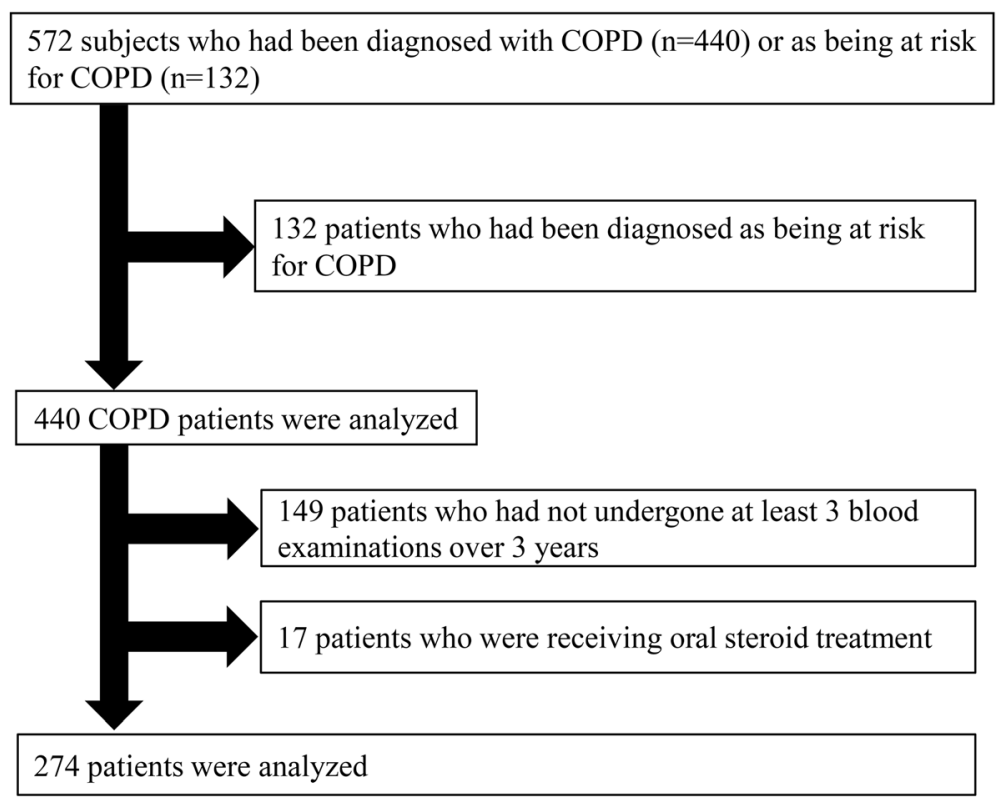

Fig. 1 Process of patient selection in this study. Data from only those COPD patients with spirometrically confirmed COPD (FEV1/forced vital capacity $(F V C)<0.7)$ who had undergone at least 3 blood examinations over 3 years and were not receiving any oral steroid treatments $(n=274)$ were analyzed. COPD, chronic obstructive pulmonary disease

\section{Statistical analysis}

Data are presented as the mean \pm standard deviation (SD) or as median (interquartile range (IQR)). Data were compared between two groups using the student $t$-test, MannWhitney $U$ test, and $X^{2}$ test. Data were compared among three or more groups using Kruskal-Wallis test and SteelDwass test. Correlations between continuous variables were evaluated using the Pearson's correlation coefficient. Univariate and multivariate logistic regression analyses were performed in order to assess the effects of factors on increasing NLR. Receiver operating characteristics (ROC) curves were constructed to assess the areas under the curves (AUCs). We investigated the optimal cutoff value by maximizing the Youden index. The data of NLR over 3 years were only used in the analysis of the annual rates of change in NLR, and in the comparison of the average of NLR among the three groups over 3 years. Differences in rates of change over time and in NLR among the 3 groups classified based on the severity of exacerbation were estimated using mixed-effects modeling with Bonferroni correction [22]. For all tests, two-sided $p$ values $<0$. 05 were considered significant. Data were analyzed using the JMP 13 software (SAS Institute, Cary, NC, USA). A mixed-effect model was applied using SPSS 23 (IBM Corporation, Armonk, NY, USA).

\section{Results}

\section{Characteristics of the study population}

Table 1 shows the baseline clinical characteristics of the study patients. The mean age of the 274 COPD patients was $72.2 \pm 7.9$ years, and $9.6 \%$ of them were current smokers. At baseline, 23.0\%, 48.9\%, 22.3\%, and 5.8\% were diagnosed as COPD grade 1, 2, 3, and 4, respectively based on the Global Initiative for Chronic Obstructive Lung Disease (GOLD) classification [31]. Baseline NLR significantly increased with the severity of COPD grade $(1.9(1.4-2.4)$ vs. 2.1 (1.5-2.6) vs. 2.3 $(2.0-3.0)$ vs. $2.7(1.9-5.3), p=0.002)$ (Table 2$)$.

Comparison of patient characteristics based on baseline NLR NLR data showed a non-normal distribution. The median baseline NLR was 2.1(1.6-2.7). Baseline characteristics of patients according to the baseline NLR are shown in Table 3. The cut-off value of NLR was arbitrarily defined based on the upper quartile points as 2.7. COPD patients with NLR $\geq 2.7(n=66)$ were older $(74.0 \pm 7.1$ years vs. 71 . $6 \pm 8.1$ years, $p=0.037)$, had a lower BMI $(22.0 \pm 3.4$ vs. $23.2 \pm 2.9, p=0.005)$ and a lower $\% \operatorname{FEV}_{1}(55.8 \pm 21.3 \%$ vs. $66.5 \pm 20.4 \%, p=0.0003)$ compared to patients with NLR $<2.7(n=199)$. Baseline NLR did not differ between current smokers and past smokers $(2.12 \pm 0.24$ vs. $2.38 \pm 0.08, p=0.30)$. On CT images, LAA\% of the patients with NLR $\geq 2.7$ tended to be higher than that of the others (18.4 (6.4-28.7) \% vs. 11.3 (5.0-23.3) \%, $p=0.093)$, while WA\% did not differ between the two groups (54.9 (46.4-59.8) \% vs. 52.4 (47.4-57.7) \%, $p=0.416)$. The COPD patients with NLR $\geq 2.7$ exhibited a significantly higher total CAT score $(13.9 \pm 7.7$ vs. $11.5 \pm 8.0$, $p=0.039)$ and SGRQ total score $(36.2 \pm 19.1$ vs. $24.8 \pm$ $18.0, p<0.001)$ compared to the others. 
Table 1 Baseline clinical characteristics of the study patients

\begin{tabular}{|c|c|}
\hline & COPD \\
\hline Number & 274 \\
\hline Gender, female, $n$ (\%) & $17(6.2)$ \\
\hline Age, years & $72.2 \pm 7.9$ \\
\hline Smoking Index, pack-years & $55.2 \pm 29.7$ \\
\hline Current smokers, $n(\%)$ & $26(9.6)$ \\
\hline $\mathrm{BMI}, \mathrm{kg} / \mathrm{m}^{2}$ & $22.9 \pm 3.1$ \\
\hline $\mathrm{FEV}_{1} / \mathrm{FVC}, \%$ & $52.4 \pm 12.3$ \\
\hline$\% \mathrm{FEV}_{1}, \%$ & $63.3 \pm 21.1$ \\
\hline GOLD grade $1 / 2 / 3 / 4, n(\%)$ & 63/134/61/16 (23.0/48.9/22.3/5.8) \\
\hline Baseline CAT score & $12.2 \pm 8.0$ \\
\hline LAMA, $n(\%)$ & $170(62.0)$ \\
\hline LABA, $n(\%)$ & $136(49.6)$ \\
\hline $\mathrm{ICS}, n(\%)$ & $93(33.9)$ \\
\hline Dose of ICS,$\mu \mathrm{g} /$ day, median & 500 \\
\hline WBC, $n$ & $6208 \pm 1566$ \\
\hline Neutrophil, \% & $60.3 \pm 8.9$ \\
\hline Neutrophil, $n$ & $3797 \pm 1320$ \\
\hline Lymphocyte, \% & $29.2 \pm 8.2$ \\
\hline Lymphocyte, $n$ & $1770 \pm 553$ \\
\hline NLR & $2.1(1.6-2.7)$ \\
\hline Eosinophil, \% & $3.4 \pm 2.6$ \\
\hline Eosinophil, $n$ & $204 \pm 150$ \\
\hline
\end{tabular}

Data are shown as mean \pm SD and median (interquartile range) COPD chronic obstructive pulmonary disease, $B M I$ body mass index, $F E V_{1}$ forced expiratory volume in one second, FVC forced vital capacity, \% FEV ratio of predicted FEV 1 , GOLD Global Initiative for Chronic Obstructive Lung Disease, CAT COPD assessment test, LAMA long-acting muscarinic antagonist, LABA long-acting $\beta_{2}$ agonist, ICS inhaled corticosteroids, WBC white blood cell, NLR Neutrophil-to-Lymphocyte ratio

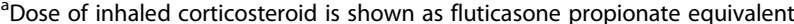

\section{Relationship between NLR and other inflammatory markers}

Baseline NLR showed a weak but significant correlation with baseline CRP $(r=0.18, p=0.003)$ and SAA $(r=0.34$, $p<0.001)$. Similarly, baseline absolute neutrophil count also correlated significantly with baseline CRP $(r=0.24$, $p<0.001)$ and baseline SAA $(r=0.31, p<0.001)$, but the

Table 2 Comparison of the baseline NLR stratified by the GOLD COPD grade

\begin{tabular}{ll}
\hline GOLD COPD grade & NLR \\
\hline 1 & $1.9(1.4-2.4)$ \\
2 & $2.1(1.5-2.6)$ \\
3 & $2.3(2.0-3.0)^{*}$ \\
4 & $2.7(1.9-5.3)$ \\
\hline Data are shown as median (interquartile range). P-values among the four \\
groups; $p=0.002,{ }^{*} p=0.008$ vs. grade 1 \\
GOLD Global Initiative for Chronic Obstructive Lung Disease, COPD chronic \\
obstructive pulmonary disease, NLR Neutrophil-to-Lymphocyte ratio
\end{tabular}

Table 3 Patient characteristics based on baseline NLR

\begin{tabular}{|c|c|c|c|}
\hline & $N L R<2.7$ & $N L R \geq 2.7$ & $p$-value \\
\hline Number & 199 & 66 & \\
\hline Gender, female, $n(\%)$ & $14(7.0)$ & $3(4.6)$ & 0.474 \\
\hline Age, years & $71.6 \pm 8.1$ & $74.0 \pm 7.1$ & 0.037 \\
\hline Smoking Index, pack-years & $53.7 \pm 28.8$ & $59.9 \pm 33.8$ & 0.159 \\
\hline Current smokers, $n(\%)$ & $21(10.7)$ & $4(6.1)$ & 0.270 \\
\hline $\mathrm{BMI}, \mathrm{kg} / \mathrm{m}^{2}$ & $23.2 \pm 2.9$ & $22.0 \pm 3.4$ & 0.005 \\
\hline $\mathrm{FEV}_{1} / \mathrm{FVC}$, (\%) & $53.8 \pm 11.8$ & $48.9 \pm 13.3$ & 0.005 \\
\hline$\% \mathrm{FEV}_{1},(\%)$ & $66.5 \pm 20.4$ & $55.8 \pm 21.3$ & 0.0003 \\
\hline LAA\%, (\%) & $11.3(5.0-23.3)$ & $18.4(6.4-28.7)$ & 0.093 \\
\hline WA\%, (\%) & $52.4(47.4-57.7)$ & $54.9(46.4-59.8)$ & 0.416 \\
\hline Baseline CAT score & $11.5 \pm 8.0$ & $13.9 \pm 7.7$ & 0.039 \\
\hline SGRQ total score & $24.8 \pm 18.0$ & $36.2 \pm 19.1$ & $<0.001$ \\
\hline LAMA, $n(\%)$ & $120(60.3)$ & $44(66.7)$ & 0.356 \\
\hline LABA, $n(\%)$ & $94(47.2)$ & $40(60.6)$ & 0.060 \\
\hline ICS, n (\%) & $63(31.7)$ & $28(42.4)$ & 0.111 \\
\hline Dose of ICS ${ }^{a}, \mu \mathrm{g} /$ day, median & 500 & 500 & 0.980 \\
\hline Eosinophil, (\%) & $3.6 \pm 2.6$ & $2.9 \pm 2.4$ & 0.080 \\
\hline Eosinophil, $n$ & $209 \pm 149$ & $188 \pm 153$ & 0.318 \\
\hline \multicolumn{4}{|c|}{$\begin{array}{l}\text { Data are shown as mean } \pm \mathrm{SD} \text { and median (interquartile range) } \\
C O P D \text { chronic obstructive pulmonary disease, NLR Neutrophil-to-Lymphocyte } \\
\text { ratio, BMI body mass index, FEV } \text { forced expiratory volume in one second, FVC } \\
\text { forced vital capacity, \% FEV } 1 \text { ratio of predicted FEV } 1, L A A \% \text { ratio of low } \\
\text { attenuation area, WA\% ratio of airway wall area, CAT COPD assessment test, } \\
\text { SGRQ St. George's Respiratory Questionnaire, LAMA long-acting muscarinic } \\
\text { antagonist, } L A B A \text { long-acting } \beta_{2} \text { agonist, ICS inhaled corticosteroids, } \\
\text { CRP C-reactive protein, SAA serum amyloid A } \\
\text { aDose of inhaled corticosteroid is shown as fluticasone propionate equivalent }\end{array}$} \\
\hline
\end{tabular}

baseline absolute lymphocyte count did not show correlation with the other inflammatory markers. The absolute neutrophil count showed no correlation with the absolute lymphocyte count $(r=0.08, p=0.214)$. These results imply that the absolute neutrophil count has a bigger impact on the value of NLR as systemic inflammation.

\section{Determinant factors of NLR}

Univariate logistic regression analysis showed that high age, \% $\mathrm{FEV}_{1}<50 \%$, low BMI $(\mathrm{BMI}<18.5)$, high CRP and high SAA were all significantly associated with NLR $\geq 2.7$ (Additional file 1: Table S1). We then performed a multivariate logistic regression analysis including the associating factors that reached significance in the univariate analysis. Because of the significant correlations between SAA and CRP $(r=0.84, p<0.001)$, SAA was excluded from the multivariate analysis. \% $\mathrm{FEV}_{1}<50 \%$, low BMI, and high CRP were found to be independent determinant factors of NLR $\geq 2.7$ (Table 4). These results imply that NLR is multifactorial, and is independently associated with severe airflow limitation, advanced age, and low BMI. Also, it is reflective of other systemic inflammation markers. 
Table 4 Predictors of high NLR (NLR $\geq 2.7)$ by multivariate logistic regression analysis

\begin{tabular}{lll}
\hline & Odds ratio $(95 \% \mathrm{Cl})$ & $P$-value \\
\hline Age & $1.04(0.99-1.08)$ & 0.063 \\
$\mathrm{BMl}<18.5$ & $2.95(1.22-7.09)$ & 0.016 \\
$\% \mathrm{FEV}_{1}<50 \%$ & $2.35(1.25-4.41)$ & 0.008 \\
CRP & $1.89(1.08-3.28)$ & 0.008 \\
\hline
\end{tabular}

NLR Neutrophil-to-Lymphocyte ratio, $B M I$ body mass index, $F E V$, forced expiratory volume in one second, \% FEV 1 ratio of predicted $\mathrm{FEV}_{1}$, CRP C-reactive protein

\section{Comparison of comorbidity prevalence according to the baseline NLR}

Prevalence of comorbidity in the study patients according to the baseline NLR is shown in Table 5. The prevalence of arteriosclerosis obliterans, cancer and cataract were tended to be higher in the NLR $\geq 2.7$ group than in the NLR $<2.7$ group (arteriosclerosis obliterans; $0.5 \%$ vs. $3.0 \%, P=0.096$, caner; $18.4 \%$ vs. $28.7 \%, \quad p=0.072$, cataract; $38.7 \%$ vs. $53.3 \%, p=0.081$ ). There were no statistical differences in the prevalence of cardiovascular disease, hypertension, diabetes. These results imply that NLR is not influenced by comorbidities in COPD patients.

Table 5 Prevalence of comorbidity in the study patients according to the baseline NLR

\begin{tabular}{|c|c|c|c|}
\hline$n(\%)$ & $\mathrm{NLR}<2.7$ & $N L R \geq 2.7$ & p-value \\
\hline Benign prostatic hyperplasia & $30(15.3)$ & $10(15.2)$ & 0.976 \\
\hline Tuberculosis & $17(8.7)$ & $5(7.6)$ & 0.781 \\
\hline Arteriosclerosis obliterans & $1(0.5)$ & $2(3.0)$ & 0.096 \\
\hline Aortic aneurysm & 7 (3.6) & $2(3.0)$ & 0.835 \\
\hline Arrhythmia & $23(11.7)$ & $6(9.1)$ & 0.554 \\
\hline Heart failure & $13(6.6)$ & $2(3.0)$ & 0.276 \\
\hline Coronary artery disease & $23(11.7)$ & $8(12.1)$ & 0.933 \\
\hline Peptic ulcer disease & $13(6.6)$ & $4(6.1)$ & 0.870 \\
\hline Dyslipidemia & $35(17.9)$ & $10(15.2)$ & 0.614 \\
\hline Diabetes mellitus & $30(15.3)$ & $8(12.1)$ & 0.525 \\
\hline Hypertension & $71(36.2)$ & $23(34.9)$ & 0.840 \\
\hline Interstitial pneumonia & $38(26.8)$ & $12(35.3)$ & 0.322 \\
\hline Pneumothorax & $10(5.1)$ & $3(4.6)$ & 0.857 \\
\hline Hyperuricemia & $16(8.2)$ & $6(9.1)$ & 0.814 \\
\hline Cerebral infarction & $11(5.6)$ & $5(7.6)$ & 0.565 \\
\hline Asthma (Asthma COPD overlap) & $38(19.5)$ & $16(24.2)$ & 0.410 \\
\hline Depression & $15(7.7)$ & $9(14.1)$ & 0.124 \\
\hline Cancer & $36(18.4)$ & $19(28.7)$ & 0.072 \\
\hline Cataract & $58(38.7)$ & $24(53.3)$ & 0.081 \\
\hline
\end{tabular}

NLR Neutrophil-to-Lymphocyte ratio, COPD chronic obstructive pulmonary disease
Longitudinal changes in NLR over 3 years

Overall, time-dependent changes in NLR showed a slight increase over 3 years $(p=0.003)$ (Fig. 2a). The distribution of the annual rate of change in NLR ( $\triangle$ NLR score/ year) over 3 years is shown in Fig. 2b. The median $\triangle$ NLR score/year was $0.05(-0.15-0.25)$.

\section{Relationship between NLR and COPD exacerbation over 3 years}

Based on the degree of exacerbations defined in our previous paper [24], the COPD subjects were classified into 3 groups: without exacerbations $(n=86)$, only mild exacerbations $(n=52)$, and moderate or severe exacerbations $(n=74)$. Among the 3 groups, the median baseline NLR was significantly higher in the moderate/severe exacerbation group compared to the exacerbation-free group but it was not significantly different when compared to the mild exacerbation group (2.4 (1.8-3.2) vs. 2.0 (1.5-2. 4) and 2.0(1.4-2.7), $p=0.010$ and 0.104 , respectively) (Fig. 3a). Univariate logistic regression analysis showed that the baseline NLR $\geq 2.7$ (OR; 2.89, $p=0.001$ ), Age (OR; 1.05, $\mathrm{p}=0.01), \% \mathrm{FEV}_{1}<50(\mathrm{OR} ; 3.23, p=0.0002)$ and LAA\% (OR; 1.05, $p=0.0004)$ were significant predictors of moderate/severe exacerbation (Additional file 1: Table S2). Multivariate logistic regression analysis was performed using risk factors that reached significance on univariate analyses. Because of the significant negative correlations between $\% \mathrm{FEV}_{1}$ and LAA $\% \quad(r=-0.47, p<0.0001)$, LAA\% were excluded from multivariate analysis. The baseline NLR $\geq 2.7$ was an independent risk factor for moderate exacerbations over 3 years (OR; 2.22, $p=0.025$ ) (Additional file 1: Table S3). ROC curves showed that the optimal cutoff for the baseline NLR for predicting moderate/ severe exacerbations was 2.7 (AUC 62.3, sensitivity $37.8 \%$, specificity $83.3 \%$ ) (Fig. 3b). Follow-up analysis over 3 years revealed that there was a significant difference in the average value of NLR among the three groups $(p=0.006)$, but the trends of NLR were comparable among the three groups over 3 years $(p=0.476)$ (Fig. 4).

\section{Comparison of receiver-operator curves for NLR, neutrophil and lymphocyte counts, and other biomarkers to stratify the severity of airflow limitation and predict future exacerbations}

The area under ROC for NLR to predict future exacerbation was $63.4 \%$ (95\% CI 55.0-71.7) and the baseline low \% $\mathrm{FEV}_{1}\left(\% \mathrm{FEV}_{1}<50 \%\right)$ was $64.2 \%$ (95\% CI 56.9-71.6), and both seemed to be better than the baseline absolute neutrophil and lymphocyte counts alone, CRP and SAA, implying that NLR was a superior predictor of the severity of airflow limitations and future exacerbations compared to the neutrophil and lymphocyte counts alone (Table 6). 


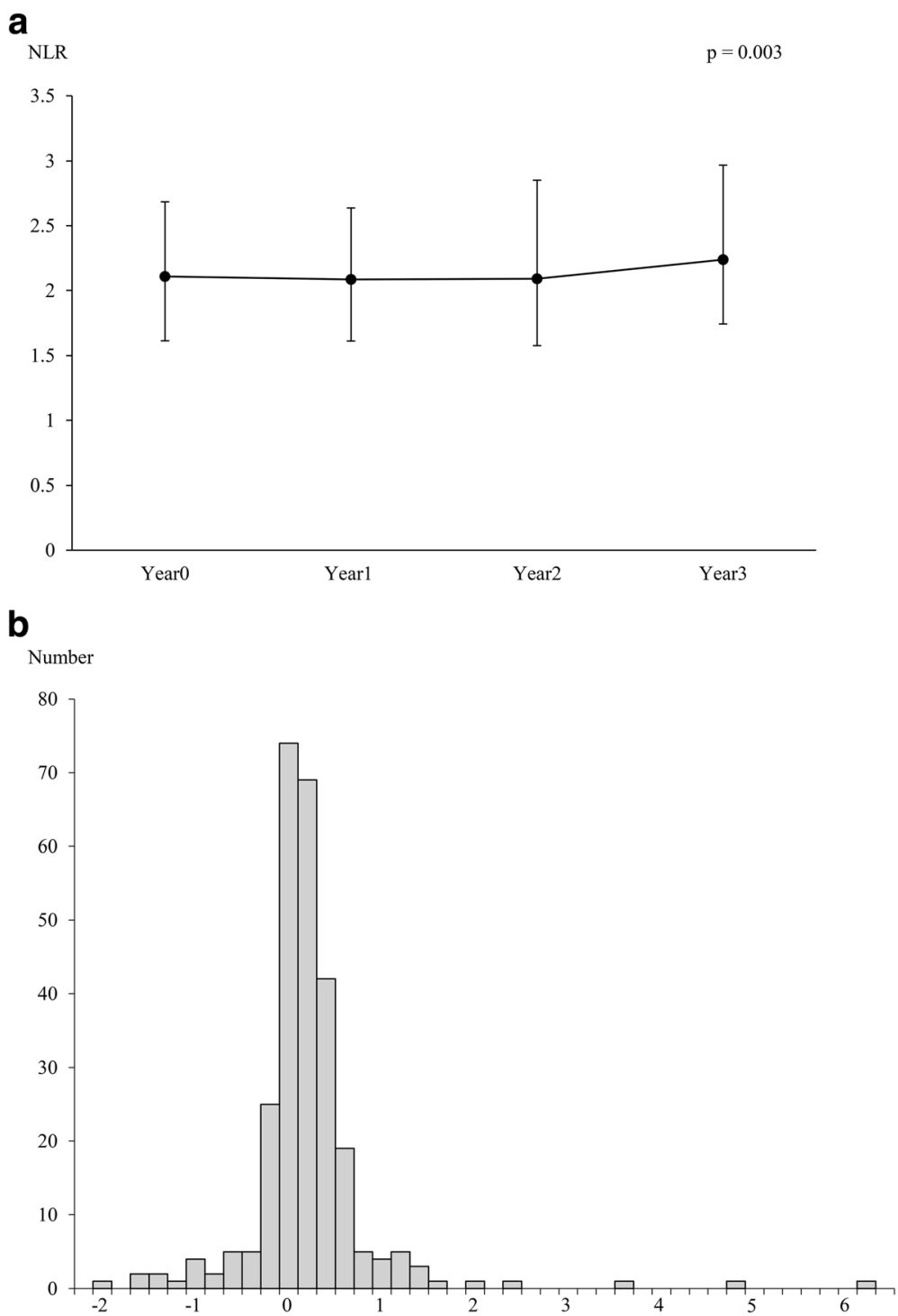

Fig. 2 Longitudinal changes in NLR. a Time-dependent changes in NLR. b The distribution of the annual rate of change in NLR ( $\Delta$ NLR score/year) over 3 years. NLR, Neutrophil-to-Lymphocyte ratio; $\Delta N L R$, the rate of change in NLR

\section{Discussion}

Mechanism of the relationship between NLR and COPD severity

Consistent with a previous report [14], in this study, we found that NLR was associated with COPD severity and exacerbations. Several studies have reported the appropriate thresholds to predict the natural history of systemic diseases other than COPD. In this study, we revealed the appropriate cut-off value of NLR as 2.7 to predict COPD severity and future exacerbations [32, 33]. The mechanisms underlying these relationships are unknown, but there could be several explanations. Firstly, it is well known that, even after smoking cessation, inflammation in the lungs continue, especially in patients with advanced COPD [34], suggesting that the persistent inflammatory response in the lungs could lead to neutrophil recruitment and activation [35]. When activated, neutrophils release a variety of serine- and metalloproteinases, which contribute to the development and progression of emphysema [36]. It has been shown that sputum neutrophilia is increased in advanced COPD and is associated with severity of airflow limitation [37]. Blood neutrophilia is a hallmark of current smokers [38] and is also a predictor of mortality in COPD patients [4]. Secondly, a relationship between bacterial colonization and exacerbations is increasingly recognized [39]. Thus, in some patients with COPD, the disturbed flora may continue to activate the innate immune 


\section{a}

$\mathrm{p}=0.010$

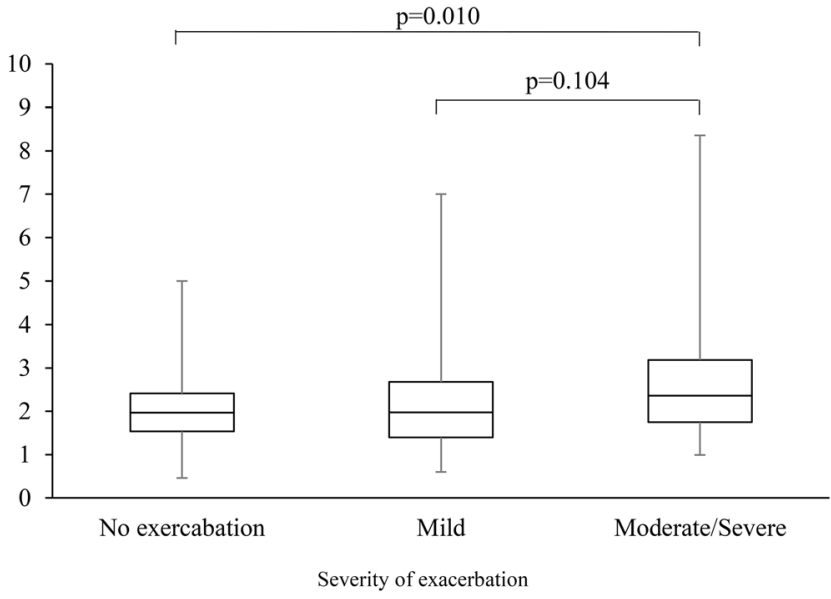

b

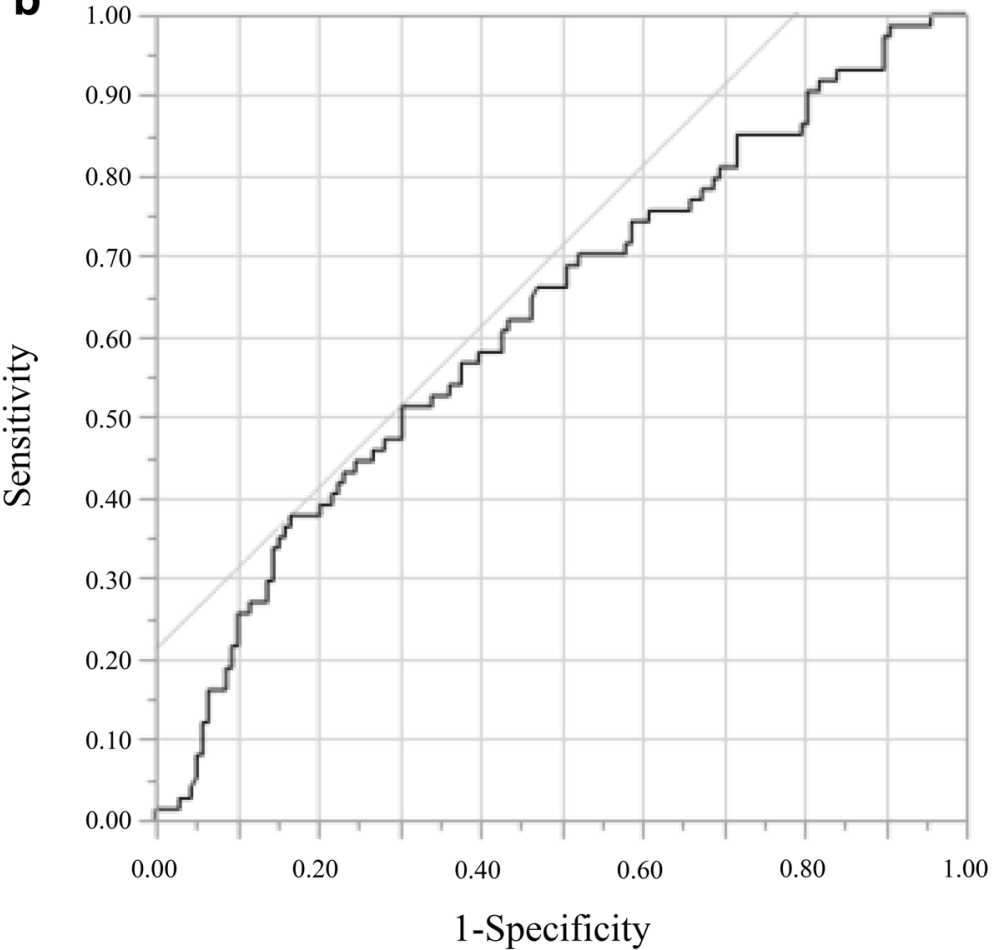

Fig. 3 Relationship between NLR and COPD exacerbation. a Comparison of median baseline NLR based on the severity of exacerbation over 3 years. $\mathbf{b}$ ROC curves of median baseline NLR in the predicting moderate or severe exacerbation. Data were compared among three groups using Steel-Dwass test. NLR, Neutrophil-to-Lymphocyte ratio

responses, perpetuating lung inflammation and blood neutrophilia. We would like to emphasize that most of the participants in this study were not current smokers. Thirdly, blood lymphopenia is associated with age [40] and poor nutritional status [41], which could also be applicable to a subset of COPD patients. Taken together, NLR along with age and nutritional status could be reflective of the systemic inflammatory condition. Weak correlations between NLR and other biomarkers might be caused by multifactorial determinants of NLR.

\section{NLR and COPD comorbidities}

It should be noted that this is the first study to assess the relationships between NLR and COPD comorbidities. Chronic systemic inflammation which is a characteristic of most comorbidities is believed to be a key factor that links COPD with its comorbidities [42]. In the ECLIPSE cohort, most COPD patients with heart disease had elevated IL-6, IL-8, and fibrinogen, while those with hypertension had elevated fibrinogen and those with diabetes had elevated CRP [19]. In our study, these comorbidities were not associated with NLR. It 


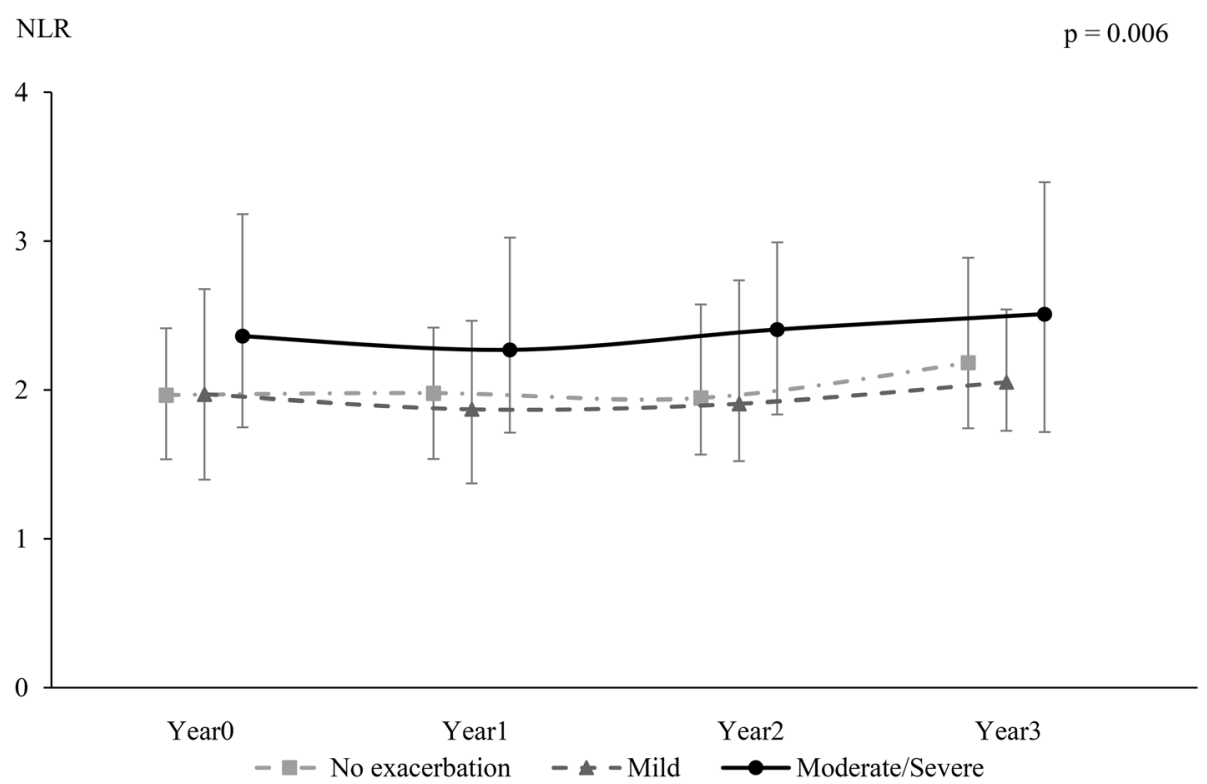

Fig. 4 Trend in NLR changes over 3 years. The trend of NLR changes in the none, mild and moderate/severe exacerbations groups was significantly different $(p=0.006$ ). Moderate/severe exacerbation vs exacerbation-free, $p=0.014$; Moderate/severe exacerbation vs mild exacerbation, $p=0.022$.

NLR, Neutrophil-to-Lymphocyte ratio

would, therefore, be unreliable to predict the presence of comorbidities by the serum inflammatory markers in COPD patients.

\section{Clinical usefulness of NLR}

NLR is a new addition to the list of inflammatory markers and has got special attention in the recent years. The value for NLR is obtained by dividing the absolute

Table 6 Comparison of the areas under ROC for NLR and other biomarkers to predict future exacerbations and low $\% \mathrm{FEV}_{1}$ $\left(\% \mathrm{FEV}_{1}<50 \%\right)$

\begin{tabular}{ll}
\hline Exacerbation & AUC (95\% Cl) \\
NLR & $63.4(55.0-71.7)$ \\
Neutrophil count & $55.2(46.3-64.2)$ \\
Lymphocyte count & $59.2(50.8-67.6)$ \\
Eosinophil count & $51.2(41.9-60.6)$ \\
CRP & $54.3(45.2-63.4)$ \\
SAA & $59.4(50.5-68.3)$ \\
\% FEV ${ }_{1}^{<}$50\% & AUC (95\% Cl) \\
NLR & $64.2(56.9-71.6)$ \\
Neutrophil count & $55.3(47.3-63.2)$ \\
lymphocyte count & $59.8(52.3-67.3)$ \\
Eosinophil count & $51.5(43.4-59.6)$ \\
CRP & $55.5(47.7-63.5)$ \\
SAA & $57.7(49.8-65.6)$ \\
\hline NLR Neutrophil-to-Lymphocyte ratio, CRP C-reactive protein, SAA serum \\
amyloid A
\end{tabular}

neutrophil count by the absolute lymphocyte count in peripheral blood samples. Moreover, this test is quite inexpensive, usually not requiring a proper setup and can be used as a screening and drug monitoring tool in population on a large scale [43].

Strategies to prevent exacerbations include targeting risk factors, addressing comorbid conditions, and giving bronchodilator therapies which include long-acting $\beta 2$ agonists (LABAs) or long-acting muscarinic antagonists (LAMAs) used alone or in combination with each other or with an inhaled corticosteroid [ICS]) [44, 45]. A number of studies have shown that the higher the blood eosinophil count, higher is the risk of exacerbation [46] and greater is the exacerbation reduction response to inhaled corticosteroids [47, 48]. In this study, although NLR was a predictor of exacerbations, blood eosinophilia was not a risk factor. This may be because the prescription rate of ICS was high in our populations than in the other cohort studies. One previous report has shown that the count and percent of blood eosinophils were not associated with the exacerbation frequency in COPD patients after carefully excluding the Asthma-COPD overlap syndrome (ACOS) patients [49]. ICS may be insufficient to prevent exacerbations in COPD patients with a high NLR, and a new prophylactic therapy should be considered. NLR may be a simple and inexpensive biomarker for detecting a neutrophilic endotype, and this endotype may be indicative of the new pharmacological strategy for treating the exacerbation. In addition to the usual care, azithromycin and roflumilast are likely candidates for prophylactic therapy in 
these patients. Azithromycin and roflumilast treated patients had lower sputum proline-glycine-proline (PGP) levels and showed a reduction in other markers of neutrophilic inflammation [50,51].

\section{Limitations of this study}

Our study had several limitations. First, although NLR was associated with exacerbations over 3 years, outcomes such as hospital admissions, emergency room visits, and mortality remain to be evaluated. Sørensen et al. reported that NLR was associated with higher mortality in moderate to very severe COPD patients [52], but it is unknown whether this result can be applied to milder COPD patients in our study. Second, blood NLR may not accurately reflect the lung inflammation of COPD patients. Low sensitivity of NLR to predict future exacerbations and airflow limitation severity may be caused by this reason. It would be preferable if we could compare blood NLR and biomarkers or cell fractionation of bronchoalveolar lavage and sputum. Third, COPD patients of the KCCR cohort study had few women (6.2\%) and were older compared to subjects of other clinical studies in Western countries. Therefore, the results may not apply to women and younger COPD patients.

\section{Conclusions}

The present study demonstrates that NLR is associated with COPD severity and exacerbations, but not with systemic comorbidity in COPD patients. For predicting exacerbations, we estimated the threshold of NLR to be 2.7 at baseline. This information could be useful in the phenotyping of COPD patients, and their careful monitoring in clinical settings. Appropriate interventions for these patients should be considered in future.

\section{Additional file}

Additional file 1: Table S1. Predictors of high NLR (NLR $\geq 2.7)$ by univariate logistic regression analysis. Table S2. Predictors of moderate or severe exacerbation by univariate logistic regression analysis. Table S3. Predictors of moderate or severe exacerbation by multivariate logistic regression analysis. (DOCX $19 \mathrm{~kb})$

\footnotetext{
Abbreviations

\%FEV 1 : Ratio of predicted FEV ${ }_{1}$; BMI: Body mass index; CAT: COPD assessment test; COPD: Chronic obstructive pulmonary disease; CRP: Creactive protein; FEV $\mathrm{F}_{1}$ : Forced expiratory volume in one second; FVC: Forced vital capacity; GERD: Gastroesophageal reflux disease; GOLD: Global Initiative for Chronic Obstructive Lung Disease; HAD-A: Seven items for anxiety of hospital anxiety and depression; HAD-D: Seven items for depression of hospital anxiety and depression; ICS: Inhaled corticosteroids; LAA\%: Ratio of Iow attenuation area; LABA: Long-acting $\beta_{2}$ agonist; LAMA: Long-acting muscarinic antagonist; NLR: Neutrophil-to-Lymphocyte ratio; SAA: Serum amyloid A; SGRQ: St. George's Respiratory Questionnaire; WA\%: Ratio of airway wall area; $\Delta N L R$ : Rate of change in NLR
}

\section{Acknowledgements}

The authors acknowledge Chiyomi Uemura for helping with data collection. The authors acknowledge all the members of the K-CCR group who participated in this study, including Saiseikai Utsunomiya Hospital, Eiju General Hospital, Tokyo Saiseikai Central Hospital, Sano Public Welfare General Hospital, Nihon Kokan Hospital, Saitama Social Insurance Hospital, Kawasaki City Ida Hospital, Saitama City Hospital, Tokyo Medical Center, Tokyo Dental College Ichikawa General Hospital, Tokyo Electric Power Company Hospital and the International Medical Welfare College Shioya Hospital.

\section{Availability of data and materials}

The data that support the findings of this study are available from the corresponding author upon reasonable request.

\section{Authors' contributions}

KS participated in the design of the study, performed the statistical analyses, and was a major contributor in writing the manuscript. SC planned the study design and contributed to interpretation of results. HN, KA, and TB conceived the study, participated in its design and coordination, and helped draft the manuscript. HI, AT, NK, TK, HK, and TT contributed to collection of data and interpretation of results. All authors read and approved the final manuscript. TB was the guarantor of is this study.

\section{Ethics approval and consent to participate}

The protocol was approved by the ethics committees of Keio University and affiliated hospitals. Written informed consent was obtained from each patient.

\section{Consent for publication}

Each patient provided written informed consent to analyze and publish his/her data.

\section{Competing interests}

The authors declare that they have no competing interests.

\section{Publisher's Note}

Springer Nature remains neutral with regard to jurisdictional claims in published maps and institutional affiliations.

\section{Author details}

'Division of Pulmonary Medicine, Department of Medicine, Keio University School of Medicine, 35 Shinanomachi, Shinjuku-ku, Tokyo 160-8582, Japan. ${ }^{2}$ Department of Medicine, Tachikawa Hospital, Tokyo, Japan. ${ }^{3}$ Division of Pulmonary Medicine, Department of Internal Medicine, Tokyo Dental College, Chiba, Japan. ${ }^{4}$ Department of Respiratory Medicine, Saitama Medical University, Saitama, Japan. ${ }^{5}$ Division of Pulmonary Medicine, Department of Medicine, Tokai University School of Medicine, Kanagawa, Japan.

Received: 2 March 2018 Accepted: 25 April 2018

Published online: 02 May 2018

\section{References}

1. Rabe KF, Watz H. Chronic obstructive pulmonary disease. Lancet. 2017;389(10082):1931-40.

2. Barnes PJ. Inflammatory mechanisms in patients with chronic obstructive pulmonary disease. J Allergy Clin Immunol. 2016;138(1):16-27.

3. Dahl M, Vestbo J, Lange P, Bojesen SE, Tybjaerg-Hansen A, Nordestgaard BG. C-reactive protein as a predictor of prognosis in chronic obstructive pulmonary disease. Am J Respir Crit Care Med. 2007;175(3):250-5.

4. Celli BR, Locantore N, Yates J, Tal-Singer R, Miller BE, Bakke P, Calverley P, Coxson $\mathrm{H}$, Crim C, Edwards LD, et al. Inflammatory biomarkers improve clinical prediction of mortality in chronic obstructive pulmonary disease. Am J Respir Crit Care Med. 2012;185(10):1065-72.

5. Mehrotra N, Freire AX, Bauer DC, Harris TB, Newman AB, Kritchevsky SB, Meibohm B, Health ABCS. Predictors of mortality in elderly subjects with obstructive airway disease: the PILE score. Ann Epidemiol. 2010;20(3):223-32.

6. Calfee CS, Ware LB, Glidden DV, Eisner MD, Parsons PE, Thompson BT, Matthay MA, National Heart B. Lung institute acute respiratory distress syndrome $\mathrm{N}$ : use of risk reclassification with multiple biomarkers improves mortality prediction in acute lung injury. Crit Care Med. 2011;39(4):711-7. 
7. Bozinovski S, Hutchinson A, Thompson M, Macgregor L, Black J, Giannakis $E_{1}$ Karlsson AS, Silvestrini R, Smallwood D, Vlahos R, et al. Serum amyloid a is a biomarker of acute exacerbations of chronic obstructive pulmonary disease. Am J Respir Crit Care Med. 2008;177(3):269-78.

8. Yonchuk JG, Silverman EK, Bowler RP, Agusti A, Lomas DA, Miller BE, TalSinger R, Mayer RJ. Circulating soluble receptor for advanced glycation end products (sRAGE) as a biomarker of emphysema and the RAGE axis in the lung. Am J Respir Crit Care Med. 2015;192(7):785-92.

9. Tamhane UU, Aneja S, Montgomery D, Rogers EK, Eagle KA, Gurm HS. Association between admission neutrophil to lymphocyte ratio and outcomes in patients with acute coronary syndrome. Am J Cardiol. 2008;102(6):653-7.

10. Azab B, Jaglall N, Atallah JP, Lamet A, Raja-Surya V, Farah B, Lesser M, Widmann WD. Neutrophil-lymphocyte ratio as a predictor of adverse outcomes of acute pancreatitis. Pancreatology. 2011;11(4):445-52.

11. Yoon NB, Son C, Um SJ. Role of the neutrophil-lymphocyte count ratio in the differential diagnosis between pulmonary tuberculosis and bacterial community-acquired pneumonia. Ann Lab Med. 2013;33(2):105-10.

12. Taylan M, Demir M, Kaya H, Selimoglu Sen H, Abakay O, Carkanat Al, Abakay A, Tanrikulu AC, Sezgi C. Alterations of the neutrophil-lymphocyte ratio during the period of stable and acute exacerbation of chronic obstructive pulmonary disease patients. Clin Respir J. 2017;11(3):311-7.

13. Gunay E, Sarinc Ulasli S, Akar O, Ahsen A, Gunay S, Koyuncu T, Unlu M. Neutrophil-to-lymphocyte ratio in chronic obstructive pulmonary disease: a retrospective study. Inflammation. 2014;37(2):374-80.

14. Lee H, Um SJ, Kim YS, Kim DK, Jang AS, Choi HS, Kim YH, Kim TE, Yoo KH, Jung KS. Association of the neutrophil-to-lymphocyte ratio with lung function and exacerbations in patients with chronic obstructive pulmonary disease. PLoS One. 2016;11(6):e0156511.

15. Furutate R, Ishii T, Motegi T, Hattori K, Kusunoki Y, Gemma A, Kida K. The neutrophil to lymphocyte ratio is related to disease severity and exacerbation in patients with chronic obstructive pulmonary disease. Intern Med. 2016;55(3):223-9.

16. Cho KM, Park H, Oh DY, Kim TY, Lee KH, Han SW, Im SA, Kim TY, Bang YJ. Neutrophil-to-lymphocyte ratio, platelet-to-lymphocyte ratio, and their dynamic changes during chemotherapy is useful to predict a more accurate prognosis of advanced biliary tract cancer. Oncotarget. 2017:8(2):2329-41

17. Jin F, Han A, Shi F, Kong L, Yu J. The postoperative neutrophil-tolymphocyte ratio and changes in this ratio predict survival after the complete resection of stage I non-small cell lung cancer. Onco Targets Ther 2016:9:6529-37

18. Vanfleteren L, Spruit MA, Wouters EFM, Franssen FME. Management of chronic obstructive pulmonary disease beyond the lungs. Lancet Respir Med. 2016;4(11):911-24.

19. Miller J, Edwards LD, Agusti A, Bakke P, Calverley PM, Celli B, Coxson HO, Crim C, Lomas DA, Miller BE, et al. Comorbidity, systemic inflammation and outcomes in the ECLIPSE cohort. Respir Med. 2013;107(9):1376-84.

20. Miyazaki M, Nakamura H, Chubachi S, Sasaki M, Haraguchi M, Yoshida S, Tsuduki K, Shirahata T, Takahashi S, Minematsu N, et al. Analysis of comorbid factors that increase the COPD assessment test scores. Respir Res. 2014;15:13.

21. Chubachi S, Sato M, Kameyama N, Tsutsumi A, Sasaki M, Tateno H, Nakamura H, Asano K, Betsuyaku T, Keio CCRG. Identification of five clusters of comorbidities in a longitudinal Japanese chronic obstructive pulmonary disease cohort. Respir Med. 2016;117:272-9.

22. Irie H, Chubachi S, Sato M, Tsutsumi A, Nakachi I, Miyao N, Nishio K, Nakamura H, Asano K, Betsuyaku T. Characteristics of patients with increasing COPD assessment test scores within 3 years. Respir Med. 2017;131:101-8.

23. Chubachi S, Nakamura H, Sasaki M, Haraguchi M, Miyazaki M, Takahashi S, Tanaka K, Funatsu Y, Asano K, Betsuyaku T, et al. Polymorphism of LRP5 gene and emphysema severity are associated with osteoporosis in Japanese patients with or at risk for COPD. Respirology. 2015;20(2):286-95.

24. Sato M, Chubachi S, Sasaki M, Haraguchi M, Kameyama N, Tsutsumi A, Takahashi S, Nakamura H, Asano K, Betsuyaku T. Impact of mild exacerbation on COPD symptoms in a Japanese cohort. Int J Chron Obstruct Pulmon Dis. 2016;11:1269-78.

25. Parr DG, Stoel BC, Stolk J, Stockley RA. Validation of computed tomographic lung densitometry for monitoring emphysema in alpha1-antitrypsin deficiency. Thorax. 2006;61(6):485-90.
26. Jones PW, Harding G, Berry P, Wiklund I, Chen WH, Kline Leidy N. Development and first validation of the COPD Assessment Test. Eur Respir J. 2009;34(3):648-54.

27. Kwon N, Amin M, Hui DS, Jung KS, Lim SY, Ta HD, Thai TTL, Yunus F, Jones PW. Validity of the COPD assessment test translated into local languages for Asian patients. Chest. 2013;143(3):703-10.

28. Hajiro T, Nishimura K, Tsukino M, Ikeda A, Koyama H, Izumi T. Analysis of clinical methods used to evaluate dyspnea in patients with chronic obstructive pulmonary disease. Am J Respir Crit Care Med. 1998;158(4):1185-9.

29. Hajiro T, Nishimura K, Tsukino M, Ikeda A, Koyama H, Izumi T. Comparison of discriminative properties among disease-specific questionnaires for measuring health-related quality of life in patients with chronic obstructive pulmonary disease. Am J Respir Crit Care Med. 1998;157(3 Pt 1):785-90.

30. Jones PW, Quirk FH, Baveystock CM, Littlejohns P. A self-complete measure of health status for chronic airflow limitation. The St. George's Respiratory Questionnaire. Am Rev Respir Dis. 1992;145(6):1321-7.

31. Global strategy for the diagnosis, management, and prevention of chronic obstructive pulmonary disease. http://goldcopd.org/gold-2017-globalstrategy-diagnosis-management-prevention-copd/. Accessed 28 Feb 2018.

32. Park CH, Han DS, Jeong JY, Eun CS, Yoo KS, Jeon YC, Sohn JH. The optimal cut-off value of neutrophil-to-lymphocyte ratio for predicting prognosis in adult patients with Henoch-Schonlein Purpura. PLoS One. 2016;11(4):e0153238.

33. Luo G, Liu C, Cheng H, Jin K, Guo M, Lu Y, Long J, Xu J, Ni Q, Chen J, et al. Neutrophil-lymphocyte ratio predicts survival in pancreatic neuroendocrine tumors. Oncol Lett. 2017;13(4):2454-8.

34. Rutgers SR, Postma DS, ten Hacken NH, Kauffman HF, van Der Mark TW, Koeter $\mathrm{GH}$, Timens W. Ongoing airway inflammation in patients with COPD who do not currently smoke. Thorax. 2000;55(1):12-8.

35. Kido T, Tamagawa E, Bai N, Suda K, Yang HH, Li Y, Chiang G, Yatera K, Mukae $\mathrm{H}$, Sin DD, et al. Particulate matter induces translocation of IL-6 from the lung to the systemic circulation. Am J Respir Cell Mol Biol. 2011;44(2):197-204.

36. Demedts IK, Morel-Montero A, Lebecque S, Pacheco Y, Cataldo D, Joos GF, Pauwels RA, Brusselle GG. Elevated MMP-12 protein levels in induced sputum from patients with COPD. Thorax. 2006;61(3):196-201.

37. O'Donnell RA, Peebles C, Ward JA, Daraker A, Angco G, Broberg P, Pierrou S, Lund J, Holgate ST, Davies DE, et al. Relationship between peripheral airway dysfunction, airway obstruction, and neutrophilic inflammation in COPD. Thorax. 2004;59(10):837-42.

38. Schwartz J, Weiss ST. Cigarette smoking and peripheral blood leukocyte differentials. Ann Epidemiol. 1994;4(3):236-42.

39. Patel IS, Seemungal TA, Wilks M, Lloyd-Owen SJ, Donaldson GC, Wedzicha JA. Relationship between bacterial colonisation and the frequency, character, and severity of COPD exacerbations. Thorax. 2002;57(9):759-64.

40. McNerlan SE, Alexander HD, Rea IM. Age-related reference intervals for lymphocyte subsets in whole blood of healthy individuals. Scand J Clin Lab Invest. 1999;59(2):89-92

41. Fraker PJ, Lill-Elghanian DA. The many roles of apoptosis in immunity as modified by aging and nutritional status. J Nutr Health Aging. 2004;8(1):56-63.

42. Fabbri LM, Rabe KF. From COPD to chronic systemic inflammatory syndrome? Lancet. 2007;370(9589):797-9.

43. Bhat T, Teli S, Rijal J, Bhat H, Raza M, Khoueiry G, Meghani M, Akhtar M, Costantino T. Neutrophil to lymphocyte ratio and cardiovascular diseases: a review. Expert Rev Cardiovasc Ther. 2013;11(1):55-9.

44. Vestbo J, Hurd SS, Agusti AG, Jones PW, Vogelmeier C, Anzueto A, Barnes PJ, Fabbri LM, Martinez FJ, Nishimura M, et al. Global strategy for the diagnosis, management, and prevention of chronic obstructive pulmonary disease: GOLD executive summary. Am J Respir Crit Care Med. 2013;187(4):347-65.

45. Pavord ID, Jones PW, Burgel PR, Rabe KF. Exacerbations of COPD. Int J Chron Obstruct Pulmon Dis. 2016;11 Spec Iss:21-30.

46. Vedel-Krogh S, Nielsen SF, Lange P, Vestbo J, Nordestgaard BG. Blood eosinophils and exacerbations in chronic obstructive pulmonary disease. The Copenhagen general population study. Am J Respir Crit Care Med. 2016;193(9):965-74.

47. Pavord ID, Lettis S, Locantore N, Pascoe S, Jones PW, Wedzicha JA, Barnes NC. Blood eosinophils and inhaled corticosteroid/long-acting beta-2 agonist efficacy in COPD. Thorax. 2016;71(2):118-25. 
48. Pascoe S, Locantore N, Dransfield MT, Barnes NC, Pavord ID. Blood eosinophil counts, exacerbations, and response to the addition of inhaled fluticasone furoate to vilanterol in patients with chronic obstructive pulmonary disease: a secondary analysis of data from two parallel randomised controlled trials. Lancet Respir Med. 2015;3(6):435-42.

49. Song JH, Lee $\mathrm{CH}$, Kim JW, Lee WY, Jung JY, Park JH, Jung KS, Yoo KH, Park YB, Kim DK. Clinical implications of blood eosinophil count in patients with non-asthma-COPD overlap syndrome COPD. Int J Chron Obstruct Pulmon Dis. 2017;12:2455-64

50. O'Reilly PJ, Jackson PL, Wells JM, Dransfield MT, Scanlon PD, Blalock JE. Sputum PGP is reduced by azithromycin treatment in patients with COPD and correlates with exacerbations. BMJ Open. 2013;3(12):e004140.

51. Wells JM, Jackson PL, Viera L, Bhatt SP, Gautney J, Handley G, King RW, Xu X, Gaggar A, Bailey WC, et al. A randomized, placebo-controlled trial of roflumilast. Effect on proline-glycine-proline and neutrophilic inflammation in chronic obstructive pulmonary disease. Am J Respir Crit Care Med. 2015;192(8):934-42.

52. Sorensen AK, Holmgaard DB, Mygind LH, Johansen J, Pedersen C. Neutrophil-to-lymphocyte ratio, calprotectin and YKL-40 in patients with chronic obstructive pulmonary disease: correlations and 5-year mortality - a cohort study. J Inflamm (Lond). 2015;12:20.

Ready to submit your research? Choose BMC and benefit from:

- fast, convenient online submission

- thorough peer review by experienced researchers in your field

- rapid publication on acceptance

- support for research data, including large and complex data types

- gold Open Access which fosters wider collaboration and increased citations

- maximum visibility for your research: over $100 \mathrm{M}$ website views per year

At BMC, research is always in progress.

Learn more biomedcentral.com/submissions 